\title{
DISEASE PROFILE OF PRISONERS ADMITTED IN SURGICAL WARD OF A TERTIARY CARE HOSPITAL IN THE VINDHYA REGION WITH HIGHLIGHTS ON INFECTIOUS DISEASES, MALNUTRITION AND OCCULT ORGAN DYSFUNCTIONS
} \author{
Rishi Kumar Garg ${ }^{8}$ \\ ${ }^{1}$ Resident, Department of Surgery, Shyam Shah Medical College, Rewa, Madhya Pradesh. \\ ${ }^{2}$ Associate Professor, Department of Surgery, Shyam Shah Medical College, Rewa, Madhya Pradesh. \\ ${ }^{3}$ Associate Professor, Department of Surgery, Shyam Shah Medical College, Rewa, Madhya Pradesh. \\ ${ }^{4}$ Associate Professor, Department of Surgery, N.S.C.B. Medical College, Jabalpur. \\ 5 Professor and HOD, Department of Surgery, Shyam Shah Medical College, Rewa, Madhya Pradesh. \\ ${ }^{6}$ Resident, Department of Surgery, Shyam Shah Medical College, Rewa, Madhya Pradesh. \\ ${ }^{7}$ Resident, Department of Surgery, Shyam Shah Medical College, Rewa, Madhya Pradesh. \\ ${ }^{8}$ Resident, Department of Surgery, Shyam Shah Medical College, Rewa, Madhya Pradesh.
}

Dhanwantari Shukla1, Rachna Guptaㄹ, Vinod Yedalwar ${ }^{3}$, Deepti Bala Sharma ${ }^{4}$, A. P. S. Gaharwar 5 , Akash Singh Chhari ${ }^{6}$, Mayank Jain ${ }^{7}$,

\section{ABSTRACT}

\section{BACKGROUND}

Health care of prisoners is one of the most neglected issues. Estimating common healthcare problems plaguing prisoners will be helpful in assessing their health status and recommending the rectifying steps.

\section{OBJECTIVES}

To estimate the prevalence of surgical diseases and occult parameters of malnutrition among prisoners and recommend the correctional measures.

\section{MATERIALS AND METHODS}

A hospital-based retrospective study was conducted on 71 prisoners admitted in surgical ward of a tertiary care centre in the Vindhya region spanning a period of 5 years (2011-2015) and the information from their case sheets was tabulated and subjected to statistical analysis.

\section{RESULTS}

Gastrointestinal diseases (23.9\%), Anorectal diseases (18.3\%), Genitourinary diseases (16.9\%), cellulitis and abscesses (12.7\%) constituted more than two-thirds of all cases. Half the patients were anaemic; $80 \%$ of the patients had hypoalbuminemia and onethird of the patients had raised Serum Bilirubin level, though they did not present with jaundice.

\section{CONCLUSION}

Surgical diseases related to infectious aetiology and poor personal hygiene are particularly common in prisoners and they suffer from a host of underlying malnutritional and systemic diseases in the form of organ dysfunction and nutritional supplementation and regular health check-up is recommended to overcome the problem.

\section{KEYWORDS}

Infectious, Anaemia, Hypoalbuminemia, Jaundice, Malnutrition, Organ Dysfunction.

HOW TO CITE THIS ARTICLE: Shukla D, Gupta R, Yedalwar V, et al. Disease profile of prisoners admitted in surgical ward of a tertiary care hospital in the Vindhya region with highlights on infectious diseases, malnutrition and occult organ dysfunctions. J. Evolution Med. Dent. Sci. 2016;5(40):2452-2455, DOI: 10.14260/jemds/2016/572

\section{INTRODUCTION}

"Prison" means any jail or place used permanently or temporarily under the general or special orders of a State Government for the detention of prisoners and includes all lands and buildings appurtenant thereto, but does not include (a) Any place for the confinement of prisoners who are exclusively in the custody of the police; (b) Any place specially appointed by the State Government under section 541 of the Code of Criminal Procedure 1882 (10 of 1882); or (c) Any place which has been declared by the State Government by general or special order to be a subsidiary jail. ${ }^{1}$ Prisoners are

Financial or Other, Competing Interest: None.

Submission 18-04-2016, Peer Review 30-04-2016,

Acceptance 05-05-2016, Published 19-05-2016.

Corresponding Author:

Dr. Dhanwantari Shukla,

F1/4, New Doctors' Colony,

Rewa-486001,

Madhya Pradesh.

E-mail: 6487sd@gmail.com

DOI: $10.14260 /$ jemds/2016/572 one of the most underserved and neglected part of the population. The normal life of prisoners is restricted, freedom of movement is curtailed and private space is limited. India is home to 1387 jails with 4,18,536 inmates against a capacity of $3,56,561$ at an occupancy rate of $117.4 \%$. MP with 11 Central Jails, 33 Dist Jails, 78 sub-jails and an open jail has 36,433 inmates against a capacity of 27,427 with an occupancy rate of $133.7 \%$. This highlights the overcrowded condition in which prisoners have to live in. ${ }^{2}$ The psychological burden, overcrowded unhygienic living conditions and neglected healthcare render the inmates to a higher risk of contracting an array of illnesses like sexually transmissible diseases, drug abuse, psychosis, community-acquired diseases and malnutrition. The present study was conducted on the prisoners admitted in surgical ward of Sanjay Gandhi Hospital during 2011-2015 with objective of estimating the prevalence of various surgical diseases they suffer from, highlighting the problem of anaemia, hypoalbuminemia and latent jaundice prevalent in this population and recommending necessary nutritional corrections. 


\section{MATERIALS AND METHODS}

This is a hospital-based retrospective study in which the details of all 71 prisoners admitted in the surgical ward of Sanjay Gandhi Memorial Hospital, Rewa, (MP) between 2011 and 2015 were collected from their case sheets stored in the Central Registration Section of the Department of Surgery, S.S. Medical College, Rewa, without applying any exclusion criteria. Information about the age, gender, presenting complaints along with their duration, all investigations done, the final diagnosis and mode of treatment done was tabulated and subjected to statistical analysis and conclusions were drawn.

\section{AIMS AND OBJECTIVES}

1. To estimate the prevalence of various surgical diseases affecting the prisoners admitted in the surgical ward of S.S. Medical College, Rewa, (MP) between 2011 and 2015.

2. To highlight the problem of anaemia, hypoalbuminemia and latent jaundice in the prisoners.

3. To recommend correctional steps to overcome this problem.

\section{RESULTS}

\begin{tabular}{|c|c|c|c|c|}
\hline $\begin{array}{l}\text { Sl. } \\
\text { No. }\end{array}$ & \multicolumn{2}{|c|}{ Characteristic } & Total & Percentage \\
\hline 1 & \multicolumn{2}{|c|}{ Number of Prisoners } & 71 & 100 \\
\hline \multirow{3}{*}{2.} & \multirow{3}{*}{ Age (In yrs.) } & $18-30$ & 25 & 35.2 \\
\hline & & $31-50$ & 33 & 46.5 \\
\hline & & $>50$ & 13 & 18.3 \\
\hline \multirow{2}{*}{3.} & \multirow{2}{*}{ Gender } & Male & 71 & 100 \\
\hline & & Female & 0 & 0 \\
\hline \multirow{4}{*}{4.} & \multirow{4}{*}{$\begin{array}{c}\text { Duration of } \\
\text { Hospitalization } \\
\text { (In days) }\end{array}$} & $<7$ & 31 & 43.7 \\
\hline & & $8-14$ & 22 & 31.0 \\
\hline & & $15-28$ & 13 & 18.3 \\
\hline & & $>28$ & 5 & 7.0 \\
\hline \multicolumn{5}{|c|}{$\begin{array}{c}\text { Table 1: Distribution of Prisoners According to } \\
\text { Age, Gender, Duration of Hospitalization }\end{array}$} \\
\hline
\end{tabular}

\begin{tabular}{|c|c|c|c|c|c|}
\hline $\begin{array}{l}\text { Sl. } \\
\text { No. }\end{array}$ & \multicolumn{3}{|c|}{ Characteristic } & Total & Percentage \\
\hline \multirow{6}{*}{1.} & \multirow{6}{*}{$\begin{array}{l}\text { Duration } \\
\text { of } \\
\text { complaint }\end{array}$} & \multirow{3}{*}{$\begin{array}{c}\text { Acute } \\
\text { conditions } \\
\text { (In days) }\end{array}$} & $<1$ & 9 & 23 \\
\hline & & & $1-7$ & 11 & 28 \\
\hline & & & $>7$ & 19 & 49 \\
\hline & & \multirow{3}{*}{$\begin{array}{c}\text { Chronic } \\
\text { conditions } \\
\text { (In } \\
\text { months) }\end{array}$} & $<1$ & 3 & 9.4 \\
\hline & & & $\begin{array}{l}1- \\
12\end{array}$ & 17 & 53.1 \\
\hline & & & $>12$ & 12 & 37.5 \\
\hline
\end{tabular}

\begin{tabular}{|c|c|c|c|c|}
\hline $\begin{array}{c}\text { Sl. } \\
\text { No } \\
.\end{array}$ & \multicolumn{2}{|c|}{ Characteristic } & $\begin{array}{c}\text { Tota } \\
\mathbf{l}\end{array}$ & $\begin{array}{c}\text { Percent- } \\
\text { age }\end{array}$ \\
\hline \multirow{4}{*}{1.} & All systems & 71 & 100 \\
\cline { 3 - 5 } & \multirow{4}{*}{$\begin{array}{c}\text { System } \\
\text { involved }\end{array}$} & Gastro-intestinal & 17 & 23.9 \\
\cline { 3 - 5 } & & Ano-rectal & 13 & 18.3 \\
\cline { 3 - 5 } & & Genito-urinary & 12 & 16.9 \\
\cline { 3 - 5 } & & $\begin{array}{c}\text { Cellulitis \& } \\
\text { Abscess }\end{array}$ & 9 & 12.7 \\
\cline { 3 - 5 } & & $\begin{array}{c}\text { Skin \& soft } \\
\text { tissue abscesses }\end{array}$ & 7 & 9.8 \\
\cline { 3 - 5 } & Injury \& Assault & 6 & 8.5 \\
\hline
\end{tabular}

\begin{tabular}{|c|c|c|c|c|}
\hline & & $\begin{array}{l}\text { Groin \& scrotal } \\
\text { swellings }\end{array}$ & 5 & 7.1 \\
\hline & & Others & 2 & 2.8 \\
\hline \multirow{5}{*}{2.} & \multirow{5}{*}{$\begin{array}{l}\text { Haemoglobi } \\
\text { n (gm\%) }\end{array}$} & $\begin{array}{c}\text { Number of } \\
\text { prisoners tested }\end{array}$ & 68 & 100 \\
\hline & & 6 or less & 4 & 5.9 \\
\hline & & $6.1-9$ & 8 & 11.8 \\
\hline & & $9.1-12$ & 22 & 32.3 \\
\hline & & $>12$ & 34 & 50 \\
\hline \multirow{3}{*}{3.} & \multirow{3}{*}{$\begin{array}{r}\text { Albumin } \\
\text { (gms\%) }\end{array}$} & $\begin{array}{c}\text { Numbers of } \\
\text { prisoners tested }\end{array}$ & 25 & 100 \\
\hline & & Normal (3.5-5.5) & 5 & 20 \\
\hline & & $<3.5$ & 20 & 80 \\
\hline \multirow{4}{*}{4.} & \multirow{4}{*}{$\begin{array}{c}\text { Serum } \\
\text { Bilirubin } \\
\text { (mg\%) }\end{array}$} & $\begin{array}{c}\text { Numbers of } \\
\text { prisoners tested }\end{array}$ & 48 & 100 \\
\hline & & 1 or less & 32 & 66.67 \\
\hline & & $1.1-\quad 2$ & 14 & 29.17 \\
\hline & & $>2$ & 2 & 4.16 \\
\hline \multirow{3}{*}{5.} & \multirow{3}{*}{$\begin{array}{l}\text { Renal } \\
\text { function }\end{array}$} & $\begin{array}{c}\text { Number of } \\
\text { prisoners tested }\end{array}$ & 60 & 100 \\
\hline & & Normal & 50 & 83.3 \\
\hline & & Abnormal & 10 & 16.7 \\
\hline \multirow{3}{*}{6.} & \multirow{3}{*}{$\begin{array}{l}\text { Blood sugar } \\
\text { level }\end{array}$} & $\begin{array}{c}\text { Number of } \\
\text { prisoners tested }\end{array}$ & 60 & 100 \\
\hline & & $\begin{array}{l}\text { Normoglycaemi } \\
\text { c }\end{array}$ & 47 & 78.3 \\
\hline & & Hyperglycaemic & 13 & 21.7 \\
\hline \multicolumn{5}{|c|}{$\begin{array}{c}\text { Table 3: Distribution of Prisoners According to Systems } \\
\text { Involved and Abnormal Lab Parameters }\end{array}$} \\
\hline
\end{tabular}

Maximum patients were of middle age group (31-50 years). This age group constituted $46.5 \%$ of the patients. Young adult age group (18-30 years) constituted $35.2 \%$ of the patients, while $18.3 \%$ of the patients belonged to geriatric age group ( $>51$ years). Average age of patients was 39 years 9 months.

All the patients were males. No female inmate was admitted during the study period. Maximum $43.7 \%$ patients needed hospitalization for less than 7 days; $31 \%$ of the patients were hospitalized for 8-14 days; $18.3 \%$ patients needed hospitalization for $15-28$ days, while $7 \%$ of the patients needed hospitalization for $>28$ days. The average duration of hospitalization was 15 days.

Among patients presenting with acute complaints like fever, vomiting, loose motion, acute pain abdomen, acute retention of urine, acute abdominal distension, obstipation, acute painful, inflamed skin or soft tissue swellings, acute bleeding PR, assault and injuries, $49 \%$ patients presented more than 7 days after onset of symptoms, $28 \%$ patients presented within 1 to 7 days and 23\% patients presented within 1 day.

Among patients presenting with chronic complaints like chronic painless skin or soft tissue lump, chronic painless uncomplicated groin and scrotal swellings, occasional PR bleeding or itching or pain and chronic pain abdomen, 53.1\% patients presented between 1 to 12 months after onset of symptoms, $37.5 \%$ pts. presented after 12 months of onset of symptoms and $9.4 \%$ pts. presented within 1 month of symptoms.

More than two-third of all patients presented with gastro-intestinal diseases (23.9\%), anorectal diseases (18.3\%), genitourinary diseases $(16.9 \%)$ and Cellulitis or abscesses $(12.7 \%)$. Other common final diagnoses include skin+soft tissue lumps (9.8\%), injury (8.5\%), uncomplicated inguinoscrotal swellings (7.1\%) and other problems (2.8\%). 
- $5.6 \%$ of the patients had Cancer.

- $2.8 \%$ of the patients were HIV positive.

- $2.8 \%$ of the patients had TB.

60 out of 71 patients under study were subjected to Random Blood Sugar testing; 8.3\% pts. were known diabetic and on anti-diabetic medication, while another $13.3 \%$ of the pts. were found to have hyperglycaemia after admission. Added together more than one-fifth of the patients were not euglycemics.

60 pts. were subjected to renal function tests; $16.6 \%$ pts. had deranged renal function.

Haemoglobin was measured in 68 out of 71 patients. Half the patients were found to be anaemic ( $\mathrm{Hb}<12 \mathrm{gm} \%)$, out of which $32.3 \%$ patients had mild anaemia (Hb 9.1-12 gm\%), $11.8 \%$ patients had moderate anaemia ( $\mathrm{Hb} 6.1-9 \mathrm{gm} \%$ ) and $5.9 \%$ patients had severe anaemia ( $\mathrm{Hb} 6 \mathrm{gm} \%$ or less).

Serum albumin was done in 25 out of 71 patients; $80 \%$ of the patients had hypoalbuminemia, while only $20 \%$ pts. had normal albumin level.

Serum bilirubin was done in 48 out of 71 patients. Though none of the pt. came with a complaint of icterus, onethird of them had raised serum bilirubin level out of whom $29.17 \%$ pts. had latent jaundice (Serum Bilirubin 1-2 mg\%) and $4.16 \%$ patients had clinical jaundice (Serum Bilirubin $>2$ $\mathrm{mg} \%$ ).

\section{DISCUSSION}

In our study, all the prisoners were male. This finding is consistent with the NCRB data according to which $95.8 \%$ of the prisoners are male. ${ }^{2}$ Sunil D. Kumar et al in their study conducted in a Central Jail in Gulbarga found that $95.7 \%$ of the prisoners were males. ${ }^{3}$ Asha A. Bellad et al in their study on prisoners conducted in the Central Jail of Hindalga, Belgaum, found that $92 \%$ inmates were males. ${ }^{4}$ This may be because our population is a male-dominated society; men have greater involvement in the matters outside the household. They move about in society more freely than women and therefore are more likely to commit crime.

In our study, $81.7 \%$ patients were in below 50 years of age. The corresponding figures of NCRB is similar and stands at $87.1 \% .^{2}$ Sunil D. Kumar et al in their study reported $76 \%$ of the prisoners under 50 years of age. ${ }^{3}$ R.K. Gupta et al in their study on inmates of Yerwada Jail, Pune, reported 81.5\% prisoners under the age of 50 years. ${ }^{5}$ A younger person can be thought to have a greater vulnerability to take deviant ways as well as greater ability to perform a crime. At this age, there are generally problems like family feuds and unemployment which might lead to an increase in crime.

The duration of hospitalization depends on the severity of illness of the patient as well as availability of healthcare services in the treating hospital in the form of infrastructure, manpower and promptness of management. According to the severity of illness, prisoners were kept hospitalized for a duration ranging from 2 days to more than 5 months with an average duration of 15 days.

About half of the patients with acute presentation presented after 7 days of the onset of complaints, while $90 \%$ of those with chronic complaints presented after 1 month of onset of complaints, which highlights the lack of health awareness among the prisoners as well as the lack of access to quality primary healthcare services.
More than $70 \%$ of the prisoners under study suffered from infective or inflammatory diseases of gastrointestinal, anorectal, genitourinary or skin and soft tissue systems. Sunil D. Kumar et al in his study found $37 \%$ of the prisoners suffered from infectious diseases. ${ }^{3}$ R.K. Gupta et al in his study reported that more than $80 \%$ of the prisoners suffered from diseases pertaining to these systems and more than half the prisoners were harbouring infections in their skin as well as gut. ${ }^{5}$ Baillargeon J et al in their study on prisoners of Texas found that infectious disease constitute $29 \%$ of the total disease burden. ${ }^{6}$ Overcrowding, poor personal hygiene and lack of access to clean water can be counted as the possible reasons behind the high prevalence of infectious diseases among the prisoners.

In our study, $5.6 \%(n=4)$ of the prisoners had cancer. Paul Mathew et al in their extensive hospital-based study of 20 years on the inmates of Texas Department of Criminal Justice found that 1953 inmates had developed Cancer between January 1, 1980 and December 31, 1999. The study estimated that nearly 3000 inmates in the U.S. are diagnosed with cancer annually and the numbers of inmates diagnosed with cancer rose proportionately as the prison population increased rapidly in the latter part of the last century. ${ }^{7}$

In our study, $2.8 \%$ of the prisoners were HIV positive. R.K. Gupta et al reported a prevalence of $0.4 \% .^{5}$ Sunil D. Kumar et al reported a figure of $0.33 \% .^{3}$ Asha A. Bellad et al in their study reported a prevalence of $1.5 \%$ for HIV positivity among prisoners. ${ }^{4}$ Kate Dolan et al in their study on HIV in Indian prisons quote a figure of $1.7 \%$ and $9.5 \%$ as prevalence of HIV positivity for male and female prisoners in India respectively and attribute unprotected sex among prisoners as a common cause behind the phenomenon. ${ }^{8}$

In the present study, $2.8 \%(\mathrm{n}=2)$ of the prisoners had TB. R.K. Gupta et al reported a prevalence of $7.5 \% \cdot{ }^{5}$ Asha A. Bellad et al reported a prevalence of $2 \% .{ }^{4}$ while Baillargeon J. et al reported a prevalence as high as $20.1 \% .^{6}$ Overcrowding and sub-standard living conditions are the possible leading factors behind the unabated transmission of the tubercular bacilli among the prisoners.

In our study, more than $21.6 \%$ patients were found to have hyperglycaemia and were either already on anti-diabetic medication or were started on anti-diabetic therapy after admission. Sunil D. Kumar et al reported a 2.33\% prevalence of Diabetes Mellitus. ${ }^{3}$ Asha A. Bellad et al reported a prevalence of $3.6 \%$ for Diabetes. ${ }^{4}$

In our study 1 in every 7 prisoners had an undiagnosed Diabetes, 1 in every 6 prisoners had an undiagnosed renal dysfunction, while one-third of all prisoners had undiagnosed liver compromise in the form of raised Serum Bilirubin and decreased Serum Albumin. This underscores the lack of routine health check-ups in prisoners and their need to pick up the cases early for effective management before the disease becomes uncontrollable.

In our study, $50 \%$ of the prisoners were anaemic. R.K. Gupta et al reported a prevalence of $20.7 \%$ for pallor and $17.6 \%$ for anaemia among prisoners and quote an average annual hospitalization rate of $5.7 \%$ for anaemia among state prisons. ${ }^{5}$ Sunil D. Kumar et al reported a prevalence of $84 \%$ for anaemia. $^{3}$

In our study, $80 \%$ of the prisoners tested for Serum Albumin level showed a value lower than normal. Olubodun JO et al in their study found that prisoners had lesser BMI $(48.1 \%$ 
as compared to $28.6 \%$ for BMI less than $20 \mathrm{~kg} / \mathrm{m}^{2}$ ), lesser mean Serum Protein (81.5 gm/L as compared to $88.7 \mathrm{gm} / \mathrm{L}$ ) and Mean Serum Albumin levels when compared with the general population and attributed the predominantly carbohydrate diet as a causative factor behind the phenomenon. ${ }^{9}$

This signifies the lack of iron and protein supplements in the diet provided to the prisoners and underscores the need of overhauling the nutritional strategy for the prisoners and providing iron and protein rich diet for all prisoners and supplementing the same for those who are deficient in these nutrients.

\section{Limitations of the Study}

This is a hospital-based study with the prisoners admitted in surgical ward acting as the study population. A populationbased study conducted on all prisoners of all jails of the region would have been more comprehensive. This is a retrospective study. A prospective study with direct interviewing and clinical examination of the patients would have been more fruitful. Inclusion of the dietary provisions and condition of hygiene after getting the relevant information from direct visit to the prisons would lead to pinpointing of the cause and making evidence-based recommendations.

\section{CONCLUSION}

"It is said that no one truly knows a nation until one has been inside its jails. A nation should not be judged by how it treats its highest citizens, but its lowest ones."

\section{Nelson Mandela. ${ }^{10}$}

Prisoners form a closed, overcrowded population overburdened with diseases. They are particularly prone to infectious diseases, substance abuse, psychiatric problems and malnutrition. In this study conducted on prisoners admitted in surgical ward, the problem of occult hypoalbuminemia, anaemia, diabetes and compromised liver and renal function have come up as an alarming problem and an eye-opener for the healthcare providers. Regular health check-up and improving the nutrition status as well as the living conditions will go a long way in improving the healthcare status of the prisoners. If the inmates are treated adequately in jails, they will return to the community health and will not burden the existing healthcare facilities of the country.

\section{RECOMMENDATION}

Though most of the patients came for other complaints, on routine investigations half the patients were found to be anaemic, 4 in every 5 had hypoalbuminemia, one-third had compromised hepatic function, one-fifths had diabetes or prediabetes and 1 in every 6 had deranged renal function. This underscores the lack of routine health check-up in prisoners and a need for regular health check-up supplemented with routine investigations, so that these features of malnutrition and end-organ failure can be picked up early and subjected to definitive therapy at a stage where it is amenable to treatment. Special care needs to be taken regarding diet of prisoners, especially pertaining to iron and protein contents. The service of a qualified nutritionist needs to be sought and protein and iron need to be provided to all prisoners and supplemented to them who are suffering from the deficiency of these nutrients. Infectious diseases and diseases related to poor hygiene have a lion's share in the prevalence of surgical diseases among prisoners. These problems stem out from the menace of overcrowding. A holistic approach to the healthcare needs to be taken and prisoners must be provided with hygienic living condition along with access to safe water and sanitation facilities.

There must be regular health awareness programmes among the prisoners in the form of workshops, symposium, didactic lectures as well as printed literature, wherein they must be taught to identify the early symptoms of common diseases so that they can report to the healthcare staff at the earliest appearance of the symptoms. The educational material must include tools to enrich the knowledge of the prisoner regarding the principles of being healthy.

\section{REFERENCES}

1. The Prisoner Act. Section 3, 1894.

2. Prison statistics India. National crime records bureau, ministry of home affairs. Govt. of India 2014.

3. Sunil D Kumar, Santosh A Kumar, Jayashree V Pattankar, et al. Health status of the prisoners in a central jail of South India. Indian J Psychol Med 2013;35(4):373-7.

4. Bellad Asha, Naik Vijaya, Mallapur M. Morbidity pattern among prisoners of central jail, Hindalga, Belgaum, Karnataka. Indian Journal of Community Medicine 2007;32(4):307.

5. Gupta RK. Health status of inmates of a prison. Indian Journal of Community Medicine 2001;26(2):86-9.

6. Baillargeon J, Black SA, Pulvino J, et al. The disease profile of texas prison inmates. Ann Epidemiol 2000;10(2):7480.

7. Paul Mathew, Linda Elting, Catherine Cooksley, et al. Cancer in an incarcerated population. Cancer 2005;104(10):2197-204.

8. Kate Dolan, Sarah Larney. HIV in Indian prisons: risk behaviour, prevalence, prevention \& treatment. Indian J Med Res 2010;132(6):696-700.

9. Olubodun JO, Akinsola HA, Adeleye OA. Prison deprivation and protein nutritional status of inmates of a developing community prison. Eur J Clin Nutr 1996;50(1):58-60.

10. Mandela N. Long walk to freedom. Boston New York London: Little, Brown and Company; 1995. 